NBER WORKING PAPER SERIES

\title{
THE MORTGAGE RATE CONUNDRUM
}

\author{
Alejandro Justiniano \\ Giorgio E. Primiceri \\ Andrea Tambalotti \\ Working Paper 23784 \\ http://www.nber.org/papers/w23784 \\ NATIONAL BUREAU OF ECONOMIC RESEARCH \\ 1050 Massachusetts Avenue \\ Cambridge, MA 02138 \\ September 2017
}

We thank, without implicating, Gene Amromin, Gadi Barlevy, Douglas Duncan, Francesco Ferrante, Andreas Fuster, Simon Gilchrist, Andrew Haughwout, Ethan Ilzetzki, Nels Lind, David Lucca, Carl Tannenbaum, Arlene Wong, as well as seminar and conference participants for comments and suggestions, and Aaron Kirkman for outstanding research assistance. The views expressed in this paper are those of the authors and do not necessarily represent those of the Federal Reserve Banks of Chicago, New York or the Federal Reserve System. Giorgio Primiceri is a consultant for the Federal Reserve Bank of Chicago and a research visitor at the European Central Bank. The views expressed herein are those of the authors and do not necessarily reflect the views of the National Bureau of Economic Research.

NBER working papers are circulated for discussion and comment purposes. They have not been peer-reviewed or been subject to the review by the NBER Board of Directors that accompanies official NBER publications.

(C) 2017 by Alejandro Justiniano, Giorgio E. Primiceri, and Andrea Tambalotti. All rights reserved. Short sections of text, not to exceed two paragraphs, may be quoted without explicit permission provided that full credit, including $\odot$ notice, is given to the source. 
The Mortgage Rate Conundrum

Alejandro Justiniano, Giorgio E. Primiceri, and Andrea Tambalotti

NBER Working Paper No. 23784

September 2017

JEL No. E32,E44,E52

\begin{abstract}
$\underline{\text { ABSTRACT }}$
We document the emergence of a disconnect between mortgage and Treasury interest rates in the summer of 2003. Following the end of the Federal Reserve expansionary cycle in June 2003, mortgage rates failed to rise according to their historical relationship with Treasury yields, leading to significantly and persistently easier mortgage credit conditions. We uncover this phenomenon by analyzing a large dataset with millions of loan-level observations, which allows us to control for the impact of varying loan, borrower and geographic characteristics. These detailed data also reveal that delinquency rates started to rise for loans originated after mid 2003, exactly when mortgage rates disconnected from Treasury yields and credit became relatively cheaper.

Alejandro Justiniano

Economic Research Department

Federal Reserve Bank of Chicago

230 S. LaSalle Street

Chicago, IL 60604

ajustiniano@frbchi.org

Giorgio E. Primiceri

Department of Economics

Northwestern University

318 Andersen Hall

2001 Sheridan Road

Evanston, IL 60208-2600

and NBER

g-primiceri@northwestern.edu

Andrea Tambalotti

Federal Reserve Bank of New York

Research and Statistics Group

33 Liberty Street, 3rd Floor

New York, NY 10045

a.tambalotti@gmail.com
\end{abstract}




\title{
THE MORTGAGE RATE CONUNDRUM
}

\author{
ALEJANDRO JUSTINIANO, GIORGIO E. PRIMICERI, AND ANDREA TAMBALOTTI
}

\begin{abstract}
We document the emergence of a disconnect between mortgage and Treasury interest rates in the summer of 2003. Following the end of the Federal Reserve expansionary cycle in June 2003, mortgage rates failed to rise according to their historical relationship with Treasury yields, leading to significantly and persistently easier mortgage credit conditions. We uncover this phenomenon by analyzing a large dataset with millions of loan-level observations, which allows us to control for the impact of varying loan, borrower and geographic characteristics. These detailed data also reveal that delinquency rates started to rise for loans originated after mid 2003, exactly when mortgage rates disconnected from Treasury yields and credit became relatively cheaper.
\end{abstract}

KEY WORDS AND PHRASES: Credit boom, housing boom, securitization, private label, subprime.

\section{INTRODUCTION}

Mortgage interest rates fell significantly between 2000 and 2006, at the same time as mortgage debt and house prices were rising to unprecedented levels. Figure 1.1 plots the behavior of the 30-year conventional mortgage rate, the most widely used measure of the economy-wide cost of mortgage financing. This rate dropped from an average of around $8 \%$ during the 1990s expansion, and about $8.5 \%$ at its peak in 2000, to around $6.5 \%$ in 2006 and 2007, at the apex of the credit boom, with rates as low as $5 \%$ in the middle of 2003 .

The mortgage rate depicted in figure 1.1 is a national average of interest rates on "firstlien prime conventional conforming home purchase mortgages with a loan-to-value of 80 percent" from Freddie Mac's Primary Mortgage Market Survey. ${ }^{1}$ But during the first half

Date: First version: May 2016. This version: August 2017.

We thank, without implicating, Gene Amromin, Gadi Barlevy, Douglas Duncan, Francesco Ferrante, Andreas Fuster, Simon Gilchrist, Andrew Haughwout, Ethan Ilzetzki, Nels Lind, David Lucca, Carl Tannenbaum, Arlene Wong, as well as seminar and conference participants for comments and suggestions, and Aaron Kirkman for outstanding research assistance. The views expressed in this paper are those of the authors and do not necessarily represent those of the Federal Reserve Banks of Chicago, New York or the Federal Reserve System.

${ }^{1}$ See http://www.freddiemac.com/pmms/abtpmms.htm. 


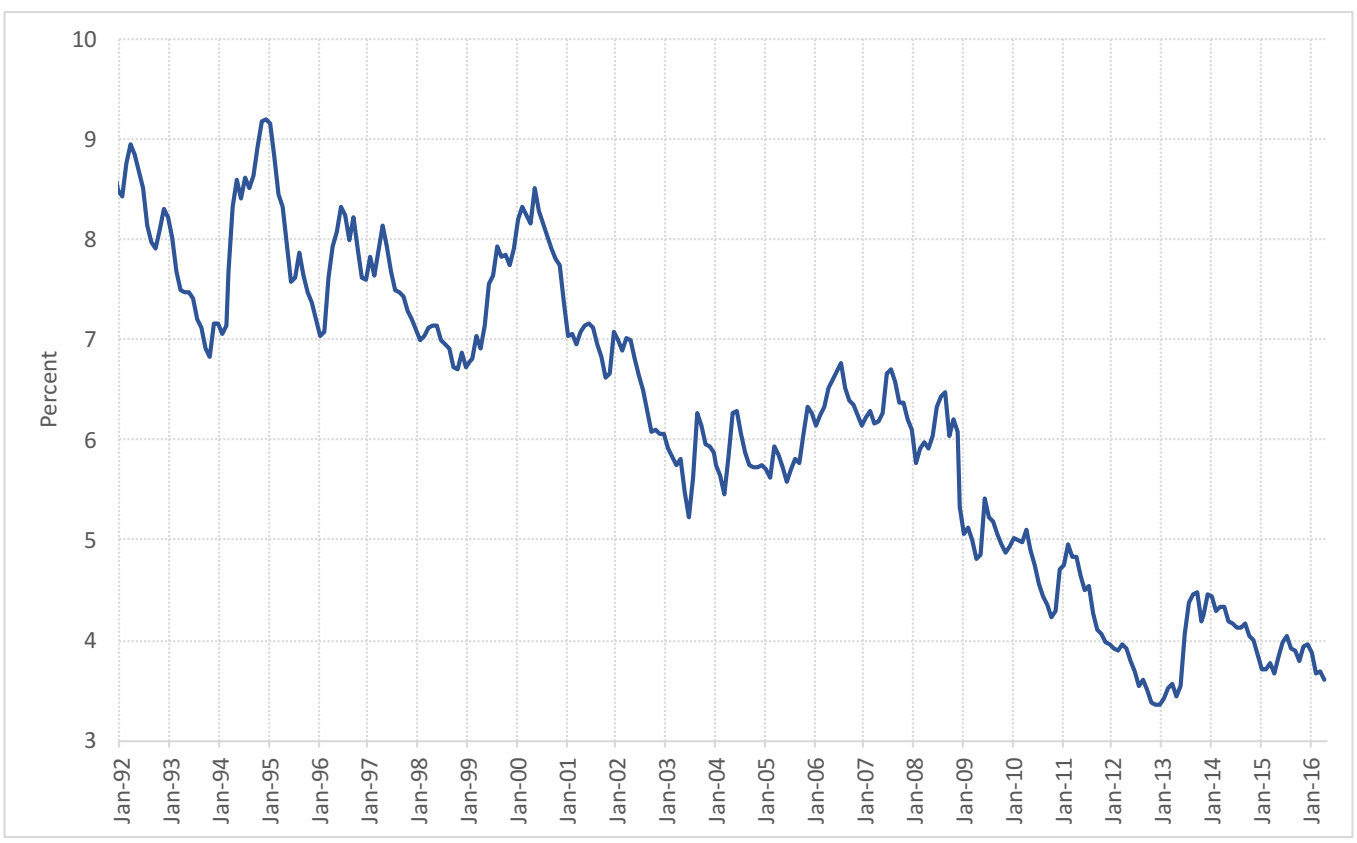

FIGURE 1.1. 30-year conventional mortgage rate.

of the 2000s, this average is likely to have become less representative of overall conditions in the U.S. mortgage market, due to the rapid diffusion over that period of non-conforming products, such as subprime, jumbo, and Alt-A mortgages with high loan-to-value (LTV) and other unconventional features. The spreading of non-conforming loans, in turn, was supported by the meteoric rise of the private-label securitization market. As shown in figure 1.2, the market share of non-agency mortgage-backed securities (MBS), which mostly collected those non-conforming mortgages, increased from about $20 \%$ in the early 2000 s to more than $50 \%$ in 2005 and 2006, before evaporating in 2008. This paper studies the extent to which this transformation in mortgage finance affected the cost of mortgage credit during the housing boom.

Using detailed loan-level data, we compute a conditional spread of mortgage rates over four Treasury market factors that summarize the level, slope, curvature and volatility of the yield curve. This spread is "conditional" because it controls for a long list of observable individual borrower and loan characteristics, such as the borrower's FICO score, the loan-tovalue ratio, and the type of mortgage contract, which should all be reflected in the mortgage rate. To the extent that those observable traits capture most of the well-documented changes in the mortgage industry in the early 2000s, this spread should provide a measure 


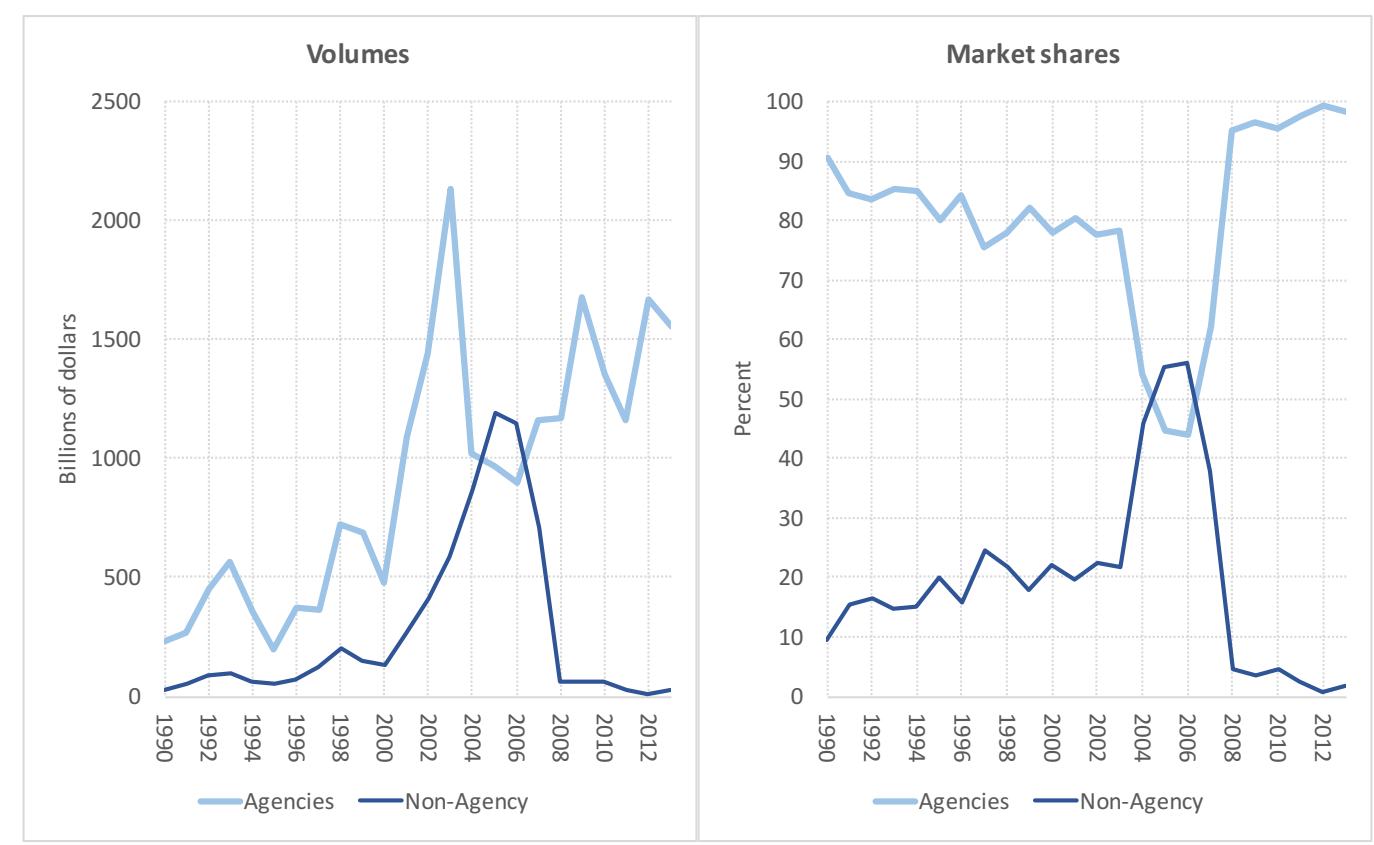

FIGURE 1.2. Securitization of residential mortgages by program: market shares and volumes of origination.

of the cost of mortgage credit that is comparable over time and across mortgages, even as the underlying composition of the market was changing. In this respect, our approach is similar in spirit to the analysis of corporate bond spreads of Gilchrist and Zakrajsek (2012).

We document that the conditional mortgage spread over Treasuries fell by about 80 basis points in the summer of 2003, signaling a significant shift in credit conditions in the mortgage market relative to Treasuries. This reduction in the conditional spread was reabsorbed only gradually over the course of the subsequent few years. Moreover, it is more pronounced for non-conforming loans included in private-label securitization pools, and particularly for subprime mortgages. ${ }^{2}$

We refer to this large, abrupt and persistent decoupling of mortgage interest rates from the prevailing conditions in the Treasury markets as the mortgage rate conundrum, since it shares some characteristics with the well-known Greenspan conundrum (2005). In particular, Greenspan was puzzled by the fact that long-term Treasury rates did not rise in response to the Federal Reserve's tightening campaign between 2004 and 2006, when the

\footnotetext{
${ }^{2}$ Antinolfi et al. (2016) also use loan-level data to study the evolution of mortgage interest rates during the housing boom as a function of loan and borrower characteristics. Differently from us, they focus on the systematic part of this relationship and its evolution over time, rather than on the conditional mortgage spread.
} 
Federal Funds rate increased from 1 to 5.25 percent. Similarly, we show that conditional mortgage rates did not budge in response to the significant steepening of the Treasury yield curve over the weeks following the FOMC meeting of June 24-25, 2003, when the Committee lowered the FFR from 1.25 to 1 percent, signaling the end of that monetary policy easing cycle.

The emergence of this conundrum, by itself, does not shed light on the factors that might have driven lending rates significantly below their historical relationship with Treasury yields, but the sharp identification of the timing of this discontinuity does. Several important events occurred in quick succession following the June FOMC meeting, which together suggest that the summer of 2003 marked a turning point in the development of the credit boom.

First, the massive refinancing wave that had been surging over the previous two years came to an abrupt conclusion in July 2003. However, this drop in refinancing activity was not followed by a fall in employment among loan brokers, in sharp contrast with what had occurred at the end of the previous two refinancing waves in 1994 and 1999. At the same time, the issuance of non-agency MBS continued to grow rapidly, even though agency securitization slowed down. These facts suggest that lenders started to push harder into subprime and other previously underserved segments of the mortgage market following the collapse of their refinancing business, in order to sustain their elevated level of activity. They did so by keeping mortgage rates low, in the face of an increase in Treasury rates, especially for those marginal borrowers that ex post appear to have contributed disproportionately to inflating the housing bubble (e.g. Landvoigt et al., 2015), and that ended up defaulting in large numbers (e.g. Mian and Sufi, 2009, Demyanyk and Van Hemert, 2011, Foote et al., 2012, Palmer, 2015, Santos, 2015, Ospina and Uhlig, 2017). In fact, we complement the literature on the evolution of loan quality during the boom by documenting that the growth rate of delinquencies, as a function of the time of mortgage origination, was subject to a break exactly around the summer of 2003, even after controlling for the evolution of borrower/loan characteristics and prevailing economic conditions. Put differently, mortgages issued after the emergence of the conundrum in mid 2003 started to become delinquent more and more frequently down the road.

The rest of the paper is organized as follows. Sections 2 and 3 describe the loan-level data used in our paper and the methodology to extract a measure of conditional spread from 
Treasuries. Section 4 presents our empirical results, while section 5 relates these findings to other important developments in mortgage markets. Section 6 studies the consequences of the conundrum in terms of loan quality and delinquency rates, and section 7 concludes highlighting the main takeaways from the paper.

\section{DATA}

The goal of this paper is to study the evolution of mortgage interest rates during the U.S. housing boom. The rich microeconomic data used in this analysis comes from two main sources, which we supplement with macroeconomic and other data as further described below. The primary dataset includes mortgages securitized by private-label issuers of MBS, which provide a comprehensive picture of the transformation in mortgage financing that took place during the 2000s. For comparison, section 4 also analyzes data on mortgages securitized by the government-sponsored enterprises (GSEs), as well as those held by banks in their portfolios.

The Private Label Securities Database (PLSD, sometimes referred to as ABS/MBS) covers the near universe of mortgages that have become part of non-agency securitization pools. This data is based on publicly available information collected by CoreLogic Loan Performance. It includes details about the characteristics of the loans and of the borrowers. For example, for most mortgages in the dataset, we observe the date of origination, the borrowing rate and other loan characteristics, as well as the value of the collateral backing the loan, the loan-to-value ratio, the credit score of the borrower, and whether she provided any income documentation. In addition, the dynamic version of the dataset follows the life of each loan, also recording its performance status every month.

The PLSD contains observations on approximately 25 million individual mortgages issued since the 1980s, but our analysis concentrates on the period between 2000 and mid 2007, which corresponds to the most intense phase of the housing boom. Moreover, the privatelabel MBS market was very thin outside this period, as show in figure 2.1. Origination of non-agency loans took off around the turn of the millennium, and completely dried up at the onset of the financial crisis in 2007.

The PLSD also provides a classification of each mortgage as prime, Alt-A or subprime, based on a flag assigned to the loan by the issuer of the MBS. Approximately two thirds of the dataset consists of subprime mortgages. This relatively large share of subprime loans 


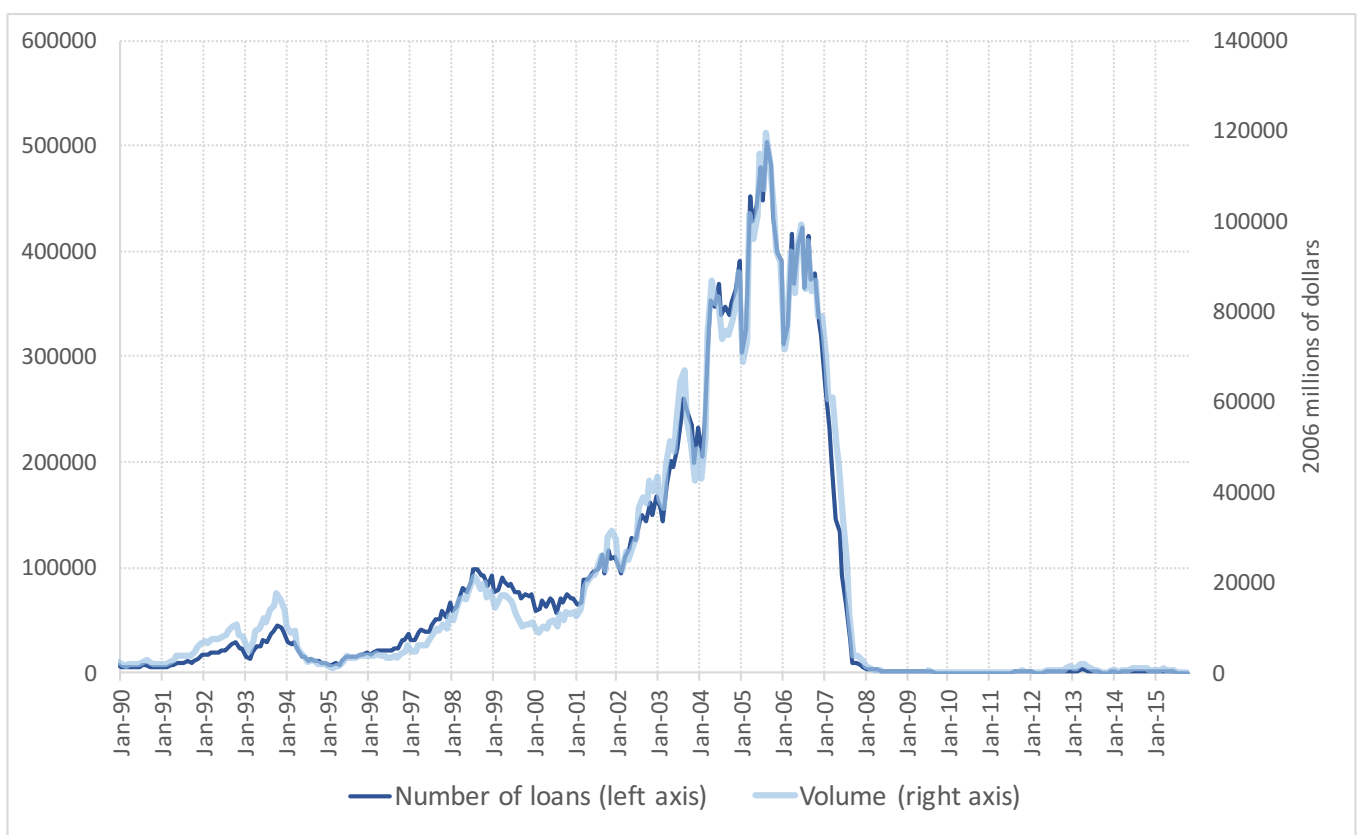

FIgURE 2.1. Mortgage origination in the PLSD.

reflects the fact that the GSEs cannot securitize them, which is why most of them ended up in private-label pools. However, it would be too simplistic to identify private-label MBS with subprime mortgages, since a substantial fraction of the loans in the PLSD are prime (11 percent) or Alt-A (25 percent).

\section{Methodology}

We use the microeconomic data described in the previous section to study the behavior of mortgage rates in the U.S. between 2000 and 2007. In particular, we are interested in analyzing the extent to which mortgage credit became progressively cheaper during this period, since "cheap credit" is one of the most often cited culprits for the housing boom and bust.

As an illustrative first pass at this question, figure 3.1 plots the spread between the average mortgage interest rate in the PLSD and the 10-year Treasury yield. This spread is informative because Treasury securities are used by originators as benchmarks to set up mortgage rates. This spread declines steadily from above 4.5 percentage points in 2001 to around 2.5 percentage points after 2004, with a particularly pronounced, abrupt and persistent fall in the middle of 2003. 


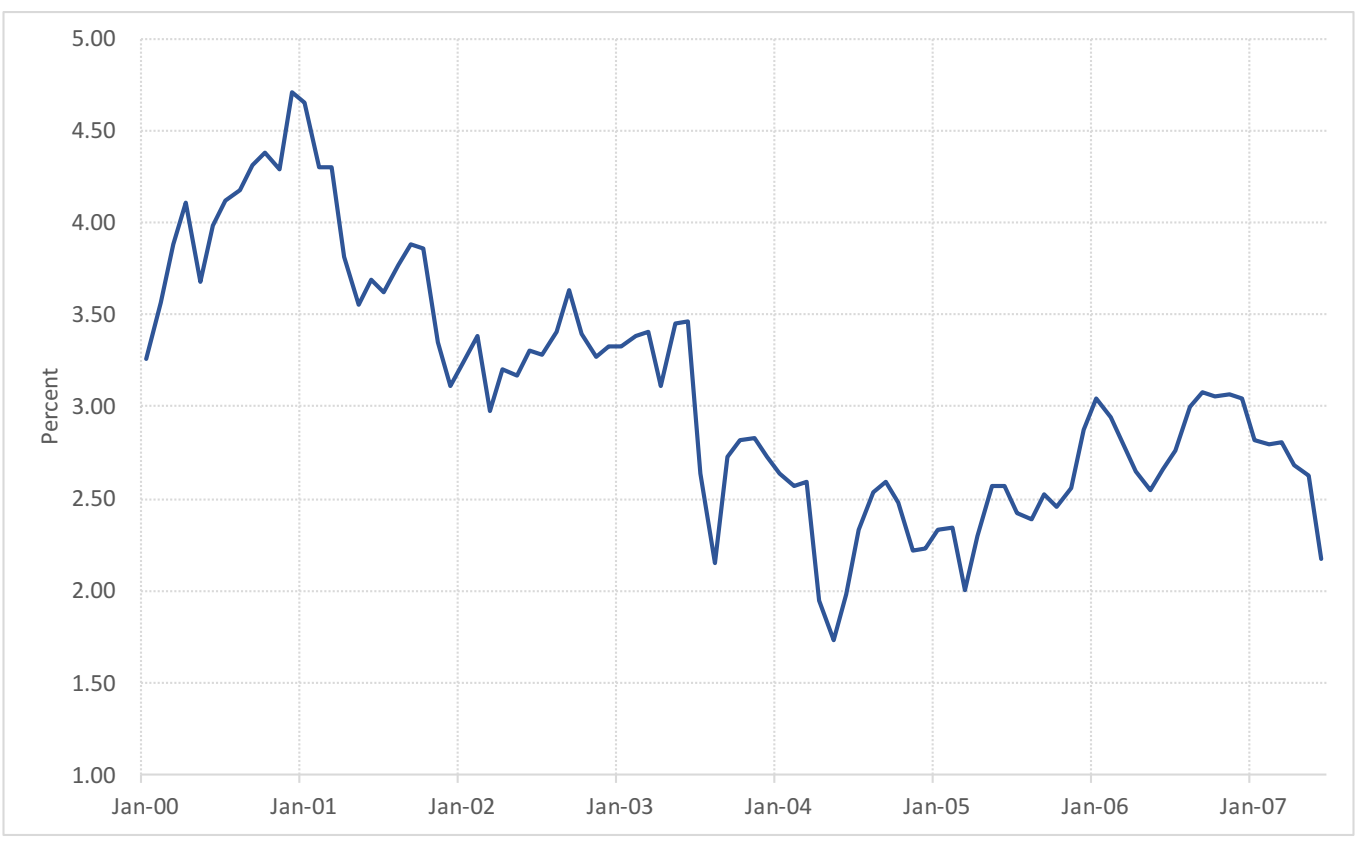

FIGURE 3.1. Spread between the average mortgage rate in the PLSD and the 10-year Treasury yield.

Aggregate data, or cross sectional averages like the ones shown in figure 3.1, however, provide a potentially misleading picture of the overall behavior of mortgage rates, because they miss the role of the well-documented changes in the mortgage finance industry during the first decade of the millennium, especially as reflected in the evolution of typical loan terms and borrower types. For example, suppose that average mortgage rates are constant over time. This observation does not necessarily imply that the price of credit is unchanged, because banks might be offering loans at the same interest rate to customers with different relevant characteristics, such as higher or lower credit worthiness. This simple consideration highlights the importance of controlling for the observed evolution of loan and borrower characteristics when studying if indeed mortgage credit became cheaper during the housing boom. Loan-level data as those in the PLSD are essential to perform this task.

To this end, we estimate the following empirical model of the evolution of mortgage rates

$$
r_{i, t}=c+f_{t-1}^{\prime} \beta+x_{i, t}^{\prime} \gamma+\text { other controls }+\varepsilon_{i, t} .
$$

In this expression, $r_{i, t}$ denotes the interest rate on mortgage $i$ at time $t$ (the month of the deal closing date), $c$ is a constant term, $x_{i, t}$ and $f_{t}$ are vectors of borrower/loan-specific and 
aggregate variables, and other controls are additional geographic and time controls, such as dummies for the month and the state in which the loan was issued. ${ }^{3}$

The vector $x_{i, t}$ is a comprehensive set of controls for loan and borrower characteristics, which should a priori be reflected in mortgage interest rates. As a guide to determine what explanatory factors to include in $x_{i, t}$, we rely on loan-rate sheets. These documents list different mortgage products offered by lenders and their interest rates, as a function of variables such as the borrower's credit score, the LTV ratio, whether the loan is a jumbo mortgage, it is intended for purchase or refinancing, and more. A list of the variables included in $x_{i, t}$ can be found in table 1 , along with some summary statistics that we will discuss in the next section.

Turning to the aggregate variables, the vector $f_{t}$ contains four term-structure factors for Treasuries. The role of these factors in the regression is to control for the comovement between mortgage and Treasury rates in a more comprehensive manner than by simply taking the difference from a long-term Treasury yield, as we have done for illustrative purposes in figure 3.1. Therefore, we interpret the residual of the regression of mortgage rates on Treasury factors as a "spread" that captures the extent to which each mortgage is cheaper, or more expensive, than what is suggested by the historical correlation with the Treasury market. More specifically, we extract the first three principal components from a panel of Treasury yields of maturities ranging from 3 months to 10 years. These principal components have the interpretation of level, slope and curvature factors, which effectively summarize the observed variation in Treasury rates over time. In addition, $f_{t}$ includes a volatility factor, computed as the realized volatility of the daily 2-year Treasury yield over a rolling 60-day window. We include this measure of interest rate volatility in the regression as a simple way to capture the effect of interest rate uncertainty on the prepayment option value embedded in mortgage rates (Gilchrist and Zakrajsek, 2012). These aggregate factors are included in the regression with a lag, to account for the fact that mortgage rates are typically "locked in" a few weeks in advance of closing, which is the point at which we observe $r_{i, t} \cdot{ }^{4}$

\footnotetext{
${ }^{3}$ We omit a geographic subscript on the interest rate to lighten the notation.

${ }^{4}$ Antinolfi et al. (2016) study the evolution of the sensitivity of mortgage interest rates to risk factors. To this end, they estimate an equation similar to (3.1), including a subset of our loan and borrower characteristics and an aggregate factor capturing the level of Treasury rates.
} 
Our strategy to study the behavior of mortgage rates focuses mostly on the residuals of equation (3.1). We interpret these residuals as a spread between actual mortgage rates and their predicted value based on aggregate factors alone, as summarized by the evolution of the four Treasury factors, after controlling for the loan and borrower characteristics included in $x_{i, t}$. Given how we construct them, we refer to these residuals as conditional mortgage rate spreads. They provide a measure of what happened to the underlying cost of mortgage credit over the housing boom, once we take into account the changes in the types of loans being originated, and in the kinds of borrowers that took out those loans, as well as in the macroeconomic and monetary policy environment as reflected in the Treasury market. Persistent negative realizations of these spreads indicate that mortgage rates are systematically lower than expected, based on their historical correlation with idiosyncratic and aggregate risk factors. We examine the time-series behavior of these spreads in the next section, where we also discuss their econometric and economic interpretation in more detail.

\section{Results}

This section presents the empirical results. We begin with some summary statistics on the characteristics of the loans and corresponding borrowers in the PLSD. We then comment briefly on the parameter estimates for equation (3.1), before analyzing the behavior of the error distribution, which is our main object of interest.

As mentioned in section 2, the analysis focuses on the period of the housing boom, between 2000 and mid 2007, during which private-label securitization flourished. In addition, we restrict attention to first-lien mortgages with a maturity of 30 years, destined to the purchase or refinancing of owner-occupied housing. ${ }^{5}$ These restrictions result in a relatively more homogeneous sample, which however still captures the main changes observed in the mortgage market over this period.

4.1. Summary statistics. Table 1 provides summary statistics for the variables included in the regressions. About two thirds of mortgages in the dataset are subprime, with the

\footnotetext{
${ }^{5}$ Second-lien mortgages usually have a substantially lower claim on the collateral, and mortgages backed by investment properties are more likely to default, since the borrower does not live in the house and thus has less at stake. Together with mortgages with maturity lower than 30 years, these loans have a substantially different risk profile among them and with respect to the those included in our sample, and hence are likely to be priced quite differently.
} 


\begin{tabular}{|c|c|c|c|c|c|c|c|c|}
\hline Year & 2000 & 2001 & 2002 & 2003 & 2004 & 2005 & 2006 & 2007 \\
\hline Interest Rate (\%) & $\begin{array}{ll}10.1 \\
\end{array}$ & 8.8 & $\overline{\overline{7.8}}$ & $\overline{7.0}$ & 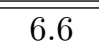 & 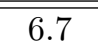 & 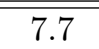 & 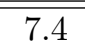 \\
\hline Loan-to-value ratio (\%) & 78.5 & 77.9 & 77.8 & 78.6 & 78.9 & 77.9 & 78.3 & 77.1 \\
\hline Borrower's FICO score & 625 & 645 & 649 & 650 & 649 & 657 & 653 & 673 \\
\hline Origination amount (log) & 11.7 & 12.1 & 12.1 & 12.1 & 12.2 & 12.3 & 12.3 & 12.6 \\
\hline Full documentation (\%) & 73 & 71 & 67 & 60 & 58 & 52 & 47 & 43 \\
\hline Prepayment penalty (\%) & 58 & 53 & 58 & 59 & 60 & 58 & 59 & 46 \\
\hline Jumbo (\%) & 24 & 36 & 32 & 25 & 21 & 22 & 20 & 35 \\
\hline \multicolumn{9}{|l|}{ Collateral Type (\%) } \\
\hline Prime & 16 & 25 & 22 & 18 & 11 & 8 & 7 & 16 \\
\hline Alt-A & 12 & 15 & 16 & 15 & 24 & 33 & 34 & 41 \\
\hline Subprime & 72 & 60 & 62 & 67 & 65 & 59 & 59 & 42 \\
\hline \multicolumn{9}{|l|}{ Purpose (\%) } \\
\hline Purchase & 47 & 38 & 34 & 34 & 41 & 44 & 44 & 34 \\
\hline Refinance w/cash-out & 41 & 43 & 44 & 46 & 46 & 46 & 46 & 47 \\
\hline Refinance & 12 & 20 & 22 & 20 & 12 & 10 & 10 & 19 \\
\hline \multicolumn{9}{|l|}{ Contract Type (\%) } \\
\hline Fixed Rate & 41 & 48 & 39 & 36 & 22 & 20 & 22 & 28 \\
\hline ARM (not back loaded) & 33 & 25 & 30 & 27 & 28 & 25 & 18 & 12 \\
\hline Interest Only (IO) & 1 & 1 & 5 & 9 & 22 & 31 & 27 & 35 \\
\hline Balloon & 0 & 0 & 0 & 0 & 0 & 3 & 17 & 14 \\
\hline Option ARM & 2 & 0 & 1 & 0 & 5 & 10 & 8 & 7 \\
\hline Other & 23 & 26 & 25 & 26 & 23 & 11 & 9 & 3 \\
\hline $\mathrm{N}$ (thousands) & 320 & 541 & 792 & 1,315 & 2,152 & 2,833 & 2,403 & 706 \\
\hline
\end{tabular}

TABLE 1. Summary statistics for 30-year, first-lien mortgages on owner-occupied houses in the PLSD. Averages or share of total, per year.

remaining third approximately equally split between prime and Alt-A. The share of AltA mortgages exhibits a marked upward trend after 2003, while the fraction of prime and subprime loans declines. Another striking feature of the data is the trend in the share of standard fixed-rate mortgages, which falls from approximately one half to one fourth of the sample. Progressively more and more loans are instead either interest-only or balloon mortgages. Combined, these unconventional products account for about 50 percent of the sample in 2007.6

\footnotetext{
${ }^{6}$ Interest-only mortgages are loans requiring only the payment of the interest on the principal, for a set term. Balloon mortgages are loans that require a final large payment (the so-called "balloon payment") at the end of the amortization period.
} 
Perhaps surprisingly, both the FICO score of the average borrower and the LTV ratio of the loans are approximately constant over time. Instead, the fraction of borrowers presenting full income documentation drops quite substantially from 73 percent in 2000 to 43 percent in 2007 consistent with the findings of Keys et al. (2012) and Mian and Sufi (2015). Overall, table 1 paints the picture of a transforming mortgage finance industry, in which non-traditional mortgage products become gradually more popular, at least until 2007. Some of these loans are riskier than more traditional products, and thus involve relatively higher interest rates. Others, such as adjustable-rate mortgages (ARM), might instead be associated with lower "teaser" rates at origination. Therefore, failing to control for these changes might lead to a misrepresentation of the behavior of mortgage rates for given loan and borrower characteristics.

4.2. Parameter estimates. Table 2 presents the coefficient estimates of equation (3.1). The first column reports the baseline, most comprehensive specification, which includes 11 million observations on fixed and variable interest rate mortgages, for both purchase and refinancing.

According to the regression, Alt-A and, especially, subprime mortgages carry a higher interest rate on average. However, this classification does not capture all dimensions of risk. In fact, even within these groups, riskier borrower profiles, such as those with higher LTV ratios, lower FICO score, or without full income documentation, as well as jumbo mortgages command higher mortgage rates. On the contrary, mortgage rates are generally somewhat lower when refinancing, regardless of whether this involves equity extraction. Finally, interest-only, ARM and balloon mortgages have substantially lower interest rates at closing, since the main feature of these contracts are smaller initial payments and enhanced initial affordability.

To allow for the possibility of varying interest rate sensitivity to risk factors across different broad classes of mortgages, columns II-V in table 2 analyze more restrictive specifications, with smaller, but more uniform samples. In particular, columns II and III distinguish between mortgages intended for purchase or refinancing, while column IV only focuses on fixed-rate mortgages. The last column is the most restrictive specification, with fixed-rate mortgages only intended for purchase. The sign of the estimated coefficients is the same across all these specifications, and their magnitude is also approximately similar. 


\begin{tabular}{|c|c|c|c|c|c|c|c|c|c|c|}
\hline \multirow[t]{2}{*}{ Specification } & \multicolumn{2}{|l|}{ I } & \multicolumn{2}{|l|}{ II } & \multicolumn{2}{|l|}{ III } & \multicolumn{2}{|l|}{ IV } & \multicolumn{2}{|l|}{$\mathrm{V}$} \\
\hline & $\begin{array}{c}\text { Purchases \& } \\
\text { Refis }\end{array}$ & & Purchases & & Refis & & FRM & & $\begin{array}{l}\text { FRM \& } \\
\text { urchases }\end{array}$ & \\
\hline Yield Curve & & & & & & & & & & \\
\hline Level & 1.032 & $*$ & 1.047 & $*$ & 1.028 & $*$ & 1.042 & $*$ & 1.061 & $*$ \\
\hline Slope & 0.724 & $*$ & 0.711 & $*$ & 0.728 & $*$ & 1.134 & $*$ & 1.208 & $*$ \\
\hline Curvature & 3.776 & $*$ & 3.347 & $*$ & 3.936 & $*$ & 3.716 & $*$ & 3.354 & $*$ \\
\hline Realized volatility & 0.139 & $*$ & 0.172 & $*$ & 0.119 & $*$ & 0.098 & $*$ & 0.125 & $*$ \\
\hline Loan and Borrower & & & & & & & & & & \\
\hline LTV ratio & 0.016 & $*$ & 0.028 & $*$ & 0.012 & $*$ & 0.014 & $*$ & 0.019 & $*$ \\
\hline $\log$ (orig. amt.) & -0.553 & $*$ & -0.489 & $*$ & -0.575 & $*$ & -0.667 & $*$ & -0.517 & * \\
\hline FICO score & -0.008 & $*$ & -0.007 & $*$ & -0.008 & $*$ & -0.007 & $*$ & -0.006 & * \\
\hline Low/no doc & 0.355 & $*$ & 0.368 & $*$ & 0.338 & $*$ & 0.245 & $*$ & 0.208 & $*$ \\
\hline Prepayment penalty & -0.055 & + & 0.023 & & -0.086 & $*$ & 0.042 & & 0.272 & * \\
\hline Jumbo & 0.406 & $*$ & 0.355 & $*$ & 0.441 & $*$ & 0.515 & $*$ & 0.390 & * \\
\hline Collateral Type & & & & & & & & & & \\
\hline Prime (base) & & & & & & & & & & \\
\hline AltA & 0.188 & $*$ & 0.262 & $*$ & 0.104 & $*$ & -0.002 & & 0.187 & $*$ \\
\hline Subprime & 0.715 & $*$ & 0.848 & $*$ & 0.587 & * & 0.355 & $*$ & 0.646 & * \\
\hline Contract Type & & & & & & & & & & \\
\hline Fixed rate (base) & & & & & & & & & & \\
\hline $\mathrm{IO}$ & -0.374 & $*$ & -0.421 & $*$ & -0.359 & $*$ & & & & \\
\hline Option ARM & -1.552 & $*$ & -1.759 & $*$ & -1.451 & $*$ & & & & \\
\hline ARM (not back loaded) & -0.102 & $*$ & -0.162 & $*$ & -0.090 & $*$ & & & & \\
\hline Balloon & -0.360 & $*$ & -0.424 & $*$ & -0.337 & $*$ & & & & \\
\hline Other & -0.031 & + & -0.162 & $*$ & 0.031 & $\#$ & & & & \\
\hline Purpose & & & & & & & & & & \\
\hline Purchase (base) & & & & & & & & & & \\
\hline Refi (cash out) & -0.067 & $*$ & & & 0.045 & + & -0.064 & $*$ & & \\
\hline Refi (no cash out) & -0.081 & $*$ & & & & & -0.084 & + & & \\
\hline$R^{2}$ & 0.621 & & 0.658 & & 0.607 & & 0.637 & & 0.657 & \\
\hline $\mathrm{N}$ & 10990130 & & 4466147 & & 6523983 & & 2815198 & & 942056 & \\
\hline
\end{tabular}

TABLE 2. Coefficient estimates in various specifications of equation (3.1). Significance levels: (\#) 10 percent, $(+) 5$ percent, $\left(^{*}\right) 1$ percent. White standard errors clustered at the state level. All specifications include a constant, state and month (Jan, Feb, etc.) dummies, as well as dummies for the property type (single family residence, condo, etc.). FRM refers to fixed-rate mortgages.

The primary objective of regression equation (3.1) is to recover a measure of mortgage rate spreads over the Treasury factors, which controls for the changes in mortgage finance 
observed in the early 2000s. Therefore, the exact interpretation of the coefficients in the regression is not crucial to the analysis of those spreads. However, the signs of these coefficients are all consistent with the hypothesis that equation (3.1) corresponds to a mortgage supply schedule, according to which riskier loan-borrower combinations are charged higher interest rates. ${ }^{7}$ This interpretation is in turn consistent with a model of the mortgage market in which all financial institutions post similar rate sheets, and the borrowers take the conditions in those sheets as given. Under these assumptions, most of the cross-sectional variation in mortgage rates would originate from the observed variability in the characteristics of loan demand, as captured by the covariates included in vector $x_{i, t}$. In any case, this interpretation of equation (3.1) is not essential to the results that follow.

4.3. Regression residuals: the conditional mortgage spread. This subsection presents the central result of the paper, which concerns the evolution of the residuals of equation (3.1) over time, what we have referred to as the conditional mortgage rate spread.

Figure 4.1 depicts the cross-sectional mean of the distribution of these residuals, for each month in the sample. By construction, the time average of this sequence of cross-sectional means is equal to zero. This time series, however, exhibits a peculiar pattern: it bounces around a positive average between 2000 and 2003, but drops sharply in the middle of 2003 . After this large fall of about 80 basis points, the mean of the residuals moves back, but only very gradually. ${ }^{8}$

Figure 4.1 also demonstrates that this phenomenon is not just due to the increasing popularity of products with attractive teaser rates. Rather, it is common to all the specifications of equation (3.1) described in table 2, including the most restrictive one that only includes fixed-rate purchase mortgages. In fact, all five specifications agree on the size and timing of the shift in the residuals, even if they often diverge in the period before.

Figure 4.2 addresses more systematically the concern that the rapid fall in residuals around the summer of 2003 might in part reflect shifts in the composition of the pool

\footnotetext{
${ }^{7}$ The only coefficient that is apparently at odds with this interpretation is the one capturing the relationship between mortgage rates and the (log) size of the loan origination amount. However, closer inspection reveals that the negative estimate in this linear model is entirely due to the effect of small loans. Since the mortgage originator pays a fixed cost to issue each loan, small loans carry relatively higher interest rates to cover that cost.

${ }^{8}$ These results are robust to a number of variants of the baseline model, such as the inclusion of the borrower's combined LTV and debt-to-income ratio, or a set of originator dummies as explicit controls. Our baseline specification omits these variables because they are only available for a small fraction of our dataset.
} 


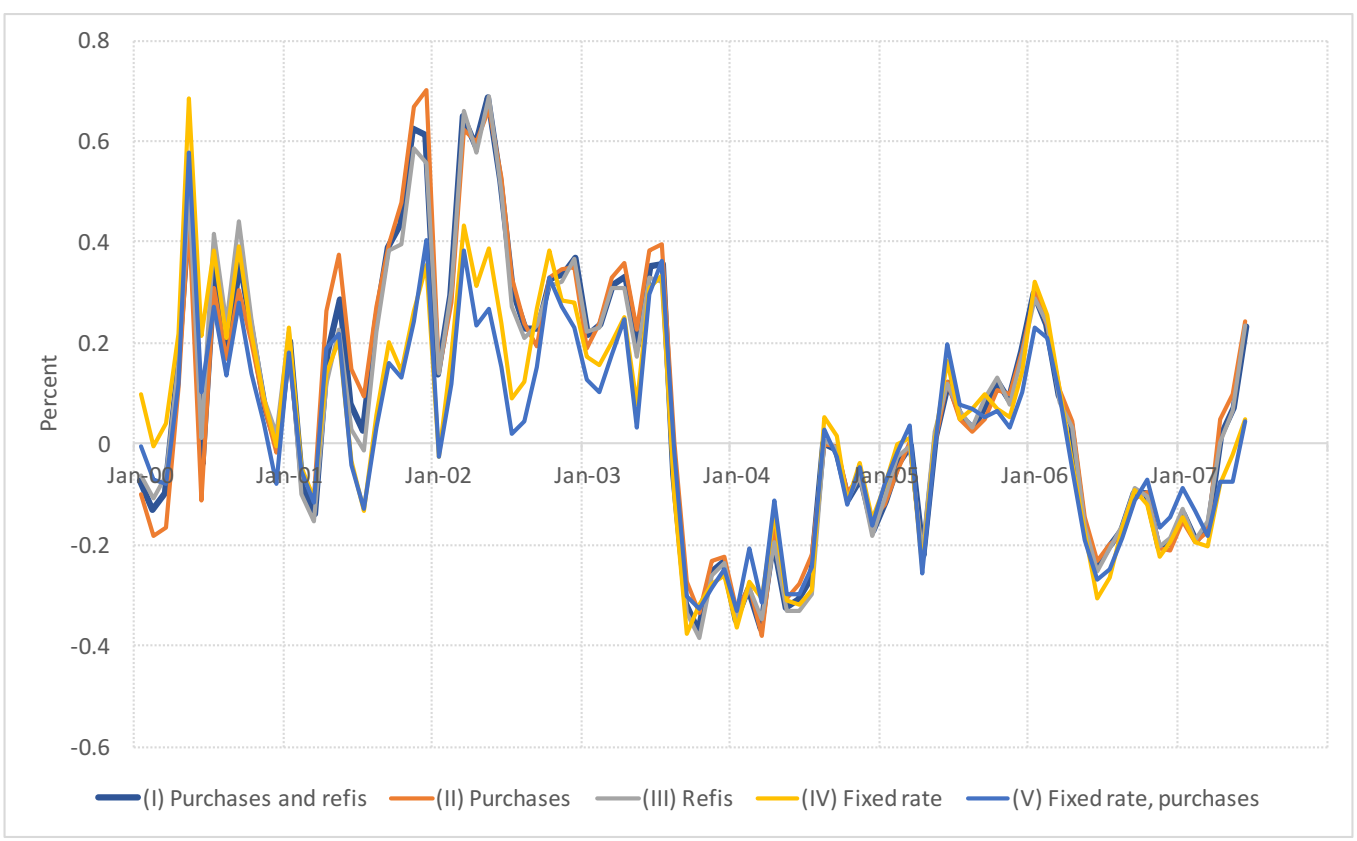

FiguRE 4.1. Average residuals in the five specifications of table 2.

of mortgages in our dataset. We do so by constructing an alternative measure of the conditional mortgage rate spread, obtained as a monthly weighted average of the mean residual across eighteen mortgage bins, with weights corresponding to the sample share of each of these categories between January 2000 and May 2003. These mortgage bins are defined by interacting prime, subprime and alt-A indicators with the six contract types listed in table 1 , because these are the dimensions along which the sample composition appears to be changing the most around 2003, albeit smoothly rather than abruptly. Figure 4.2 compares this alternative version of the spread with our baseline. The very small differences between these two measures indicate that compositional changes are unlikely to be a major driver of the evolution of the conditional spread in the summer of 2003 and after.

In principle, these persistently low residuals could be due to variation in unobserved borrower characteristics. In practice, however, there are at least two compelling reasons to rule out this interpretation of our results. First, the fall of the conditional mortgage spread in the summer of 2003 is very abrupt. Therefore, to explain it, we would need an equally sudden change in unobserved borrower characteristics around the same time, which does not seem particularly plausible. Second, to rationalize the estimated lower mortgage spreads, unobserved borrower quality should have improved over the boom after 2003, which is at 


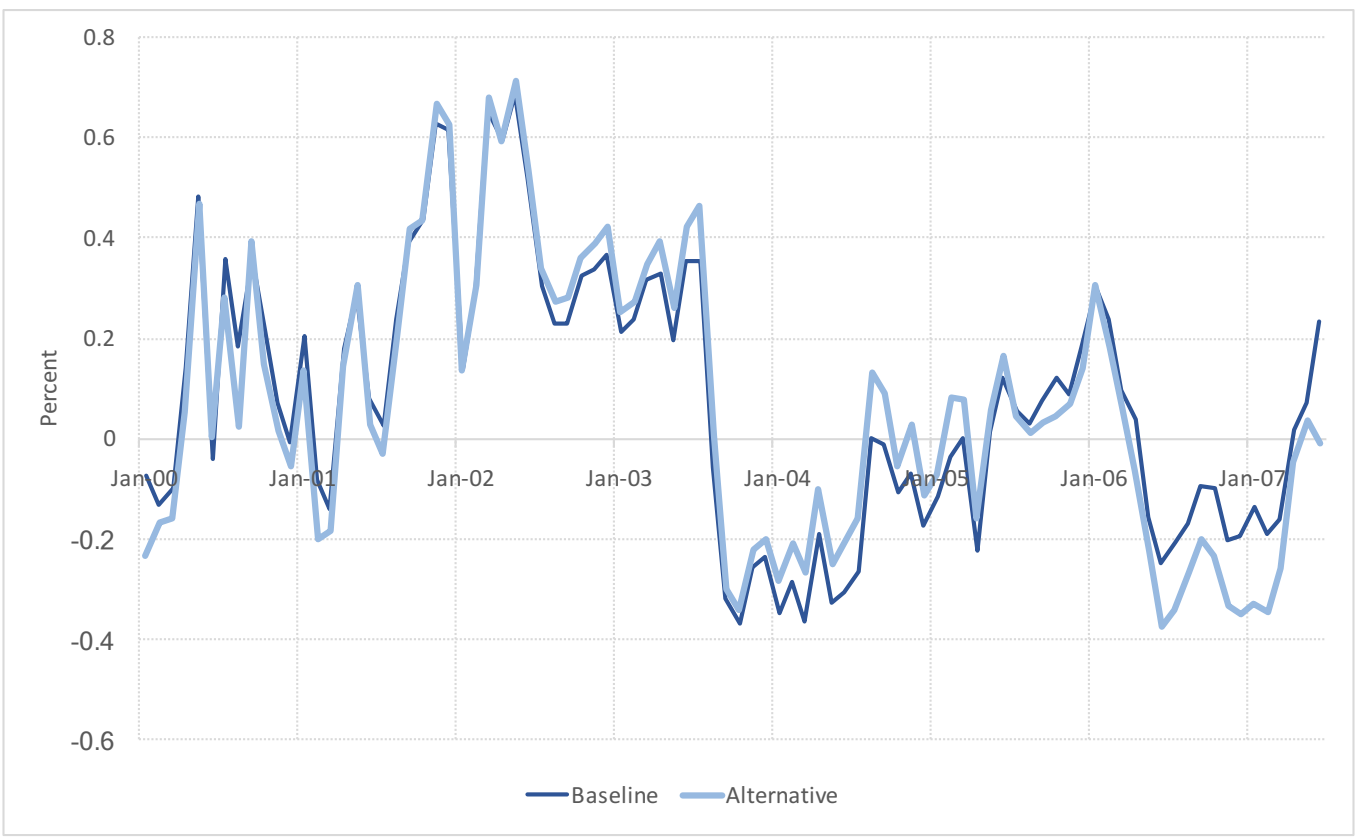

FIGURE 4.2. Average residuals: baseline and alternative measure using the preJune-2003 weights of eighteen mortgage categories.

odds with the conventional and anecdotal views. In fact, in section 6 we will document that unobserved quality - as measured by ex-post loan performance - started to deteriorate, not improve, after the summer of 2003.

A more natural interpretation of our finding is that, in the middle of 2003, mortgage credit became significantly and persistently cheaper with respect to the prevailing conditions in the Treasury market, even after controlling for the concomitant evolution of observable loan and borrower characteristics. We refer to this decoupling between conditions in the mortgage and Treasury markets as the mortgage rate conundrum.

4.4. The mortgage rate conundrum. This section attempts to shed more light on the origin of the mortgage rate conundrum described above. The question that we want to address is to what extent the abrupt fall in the conditional spreads in the middle of 2003 shown in figure 4.1 was due to an actual reduction in mortgage rates, or to changes in the conditioning factors. The main conclusion of this investigation is that the conundrum emerged due to the lack of response of mortgage rates to the developments in Treasury markets that followed the FOMC meeting of June 2003, rather than to an abrupt change in mortgage rates themselves. The peculiar behavior of mortgage rates identified above, therefore, is reminiscent of the puzzling stability of long-term Treasury yields in the face of rising 


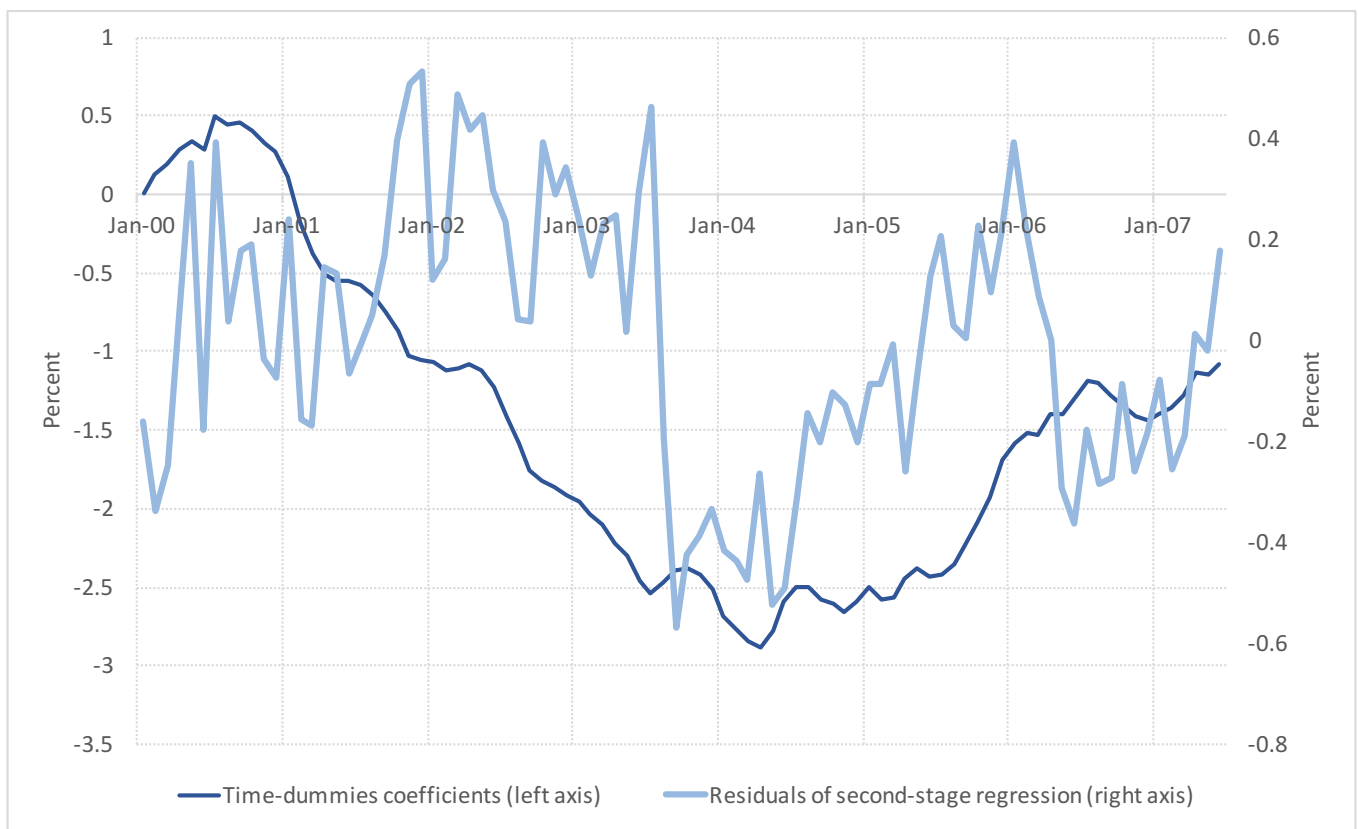

FIGURE 4.3. Estimated coefficients on time dummies and residuals of secondstage regression on Treasury and volatility factors.

policy rates that emerged between 2004 and 2006, Alan Greenspan's famous conundrum (Greenspan, 2005).

To illustrate the relative behavior of mortgage rates and Treasury yield factors, it is useful to estimate equation (3.1) in two steps. In the first step, we re-estimate the model excluding the aggregate factors, $f_{t}$, but including a set of time dummies instead. By construction, these time dummies force the cross-sectional average of the regression residuals to be zero at each point in time. Figure 4.3 plots the behavior over time of the coefficients on the time dummies in the baseline specification that includes all mortgages. This time series captures the evolution of average mortgage rates (up to a constant term), after controlling for all the loan and borrower characteristics included in $x_{i, t}$. This average conditional mortgage rate falls steadily between mid 2001 and mid 2004, by about 3.5 percentage points in total, consistent with the idea that mortgage credit became significantly cheaper over this period.

Of course, conditions in the Treasury market were also changing at the same time, which account for the bulk of the movements in the time-dummy coefficients. To control for the effect of these changes in the Treasury market, the second step of the procedure is to regress 
the time effect on the term-structure and volatility factors $f_{t} \cdot{ }^{9}$ Figure 4.3 plots the residuals of this second-stage time series regression, which look very similar to the average residuals of the baseline regression reported in figure 4.1.

Comparing the two series in figure 4.3, we see that the abrupt fall in residuals that occurs in mid 2003 was not due to a sudden fall in average conditional mortgage rates. The time effect briefly stops falling around that time, and even rises somewhat for a few months, but this movement is swamped by the drop in the residuals. What happened, therefore, is that credit conditions tightened significantly in the Treasury market, as a response to the end of the monetary policy easing cycle in June 2003. But mortgage rates barely moved in response.

To support this evidence, we run a second experiment, motivated by the fact that the estimated model (3.1) fits the data better between 2000 and mid 2003 than afterwards. In particular, the average residuals over that period appear to fluctuate around a constant without any evident pattern. This evidence suggests that the peculiar dynamics in the second part of the sample might be due to a break in the coefficients of equation (3.1). To verify this statement, we first estimate our baseline specification with data from 2000 to June 2003. We then project mortgage rates after mid 2003 conditional on the estimated coefficients and the realizations of the regressors after mid 2003. Figure 4.4 plots the average difference between the actual and projected values of the mortgage rates. In the first part of the sample, this difference is just the average of the regression residuals, which fluctuates around a roughly zero mean. After mid 2003, however, a large and persistent discrepancy between actual and projected rates emerges. This discrepancy has a similar magnitude and time series pattern as the residuals plotted in figure 4.1. It hovers between 60 and 80 basis points into 2005, and it reverts to positive territory only in 2006.

Taken together, the two empirical exercises that we just described lead us to conclude that

(1) The relationship between conditional mortgage rates and Treasury factors was subject to an abrupt break in the middle of 2003 ;

\footnotetext{
${ }^{9}$ The R-squared of this regression is 92 percent. In principle, this procedure suffers from a generatedregressor problem, but we have so many observations to estimate the coefficients on the time dummies, that their standard errors are effectively equal to zero.
} 


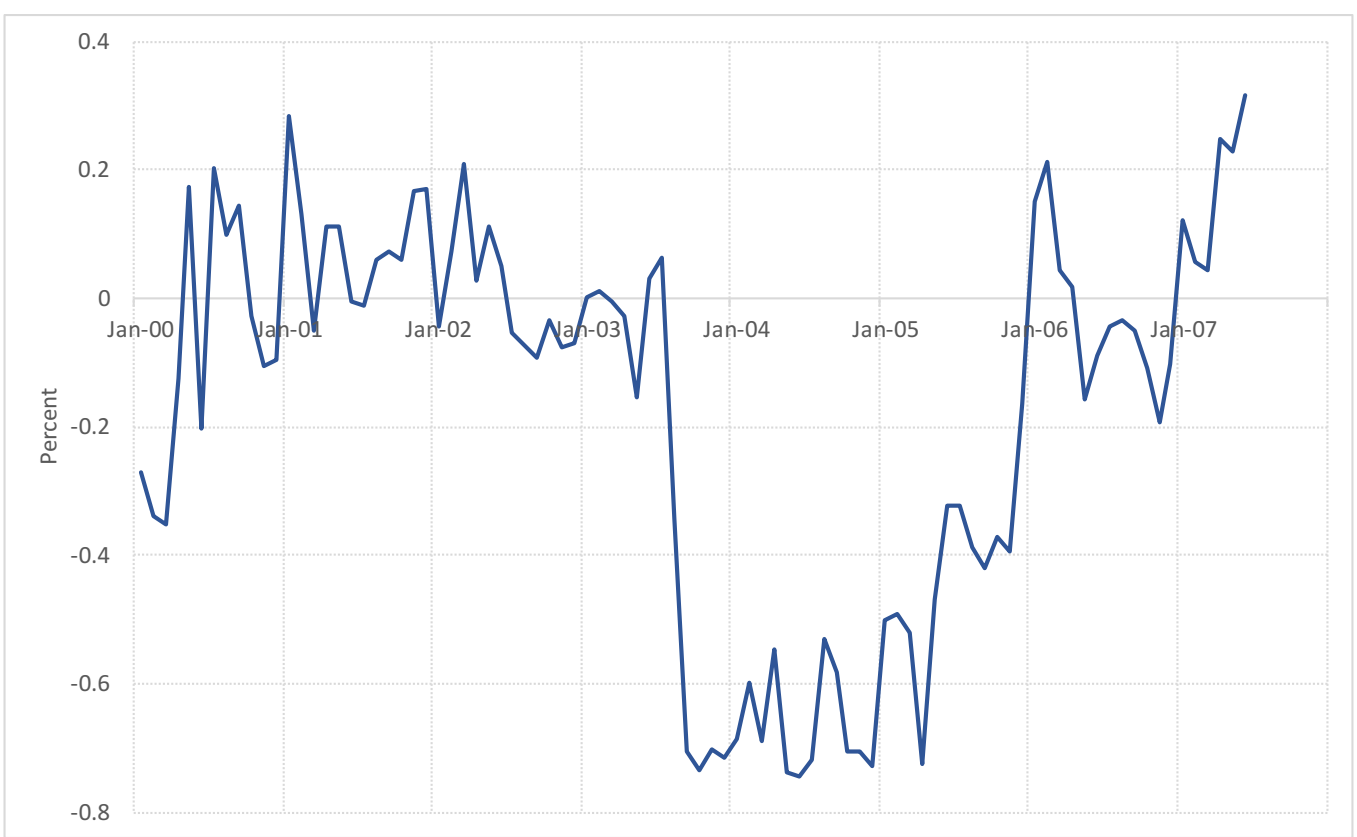

FIgURE 4.4. Average difference between actual and counterfactual mortgage rates.

(2) This break reflects a tightening of credit conditions in the Treasury market, as captured by changes in the factors included in $f_{t}$, rather than an abrupt fall in mortgage interest rates.

We investigate next the extent to which this break was a widespread phenomenon across different types of mortgages, before analyzing some of the factors that might have triggered it.

4.5. How common was the conundrum? Figure 4.5 plots the evolution of the average residuals in alternative specifications of equation (3.1), in which we focus separately on prime, Alt-A and subprime mortgages. The drop in residuals in the summer of 2003 is evident in all these regressions, but it is more pronounced for subprime mortgages, which is consistent with the evidence of Demyanyk and Van Hemert (2011).

Next, we study if this phenomenon was specific to the private-label market, or also common to mortgages sold to the GSEs or held in banks portfolios. We investigate this question with a different dataset, the Residential Mortgage Servicing Database (RMSD). This dataset covers the universe of mortgages issued by the 10 largest originators in the U.S. (now fewer due to mergers), which represent about two-thirds of installment loans in the residential mortgage market. Overall, this larger database contains about 151 million 


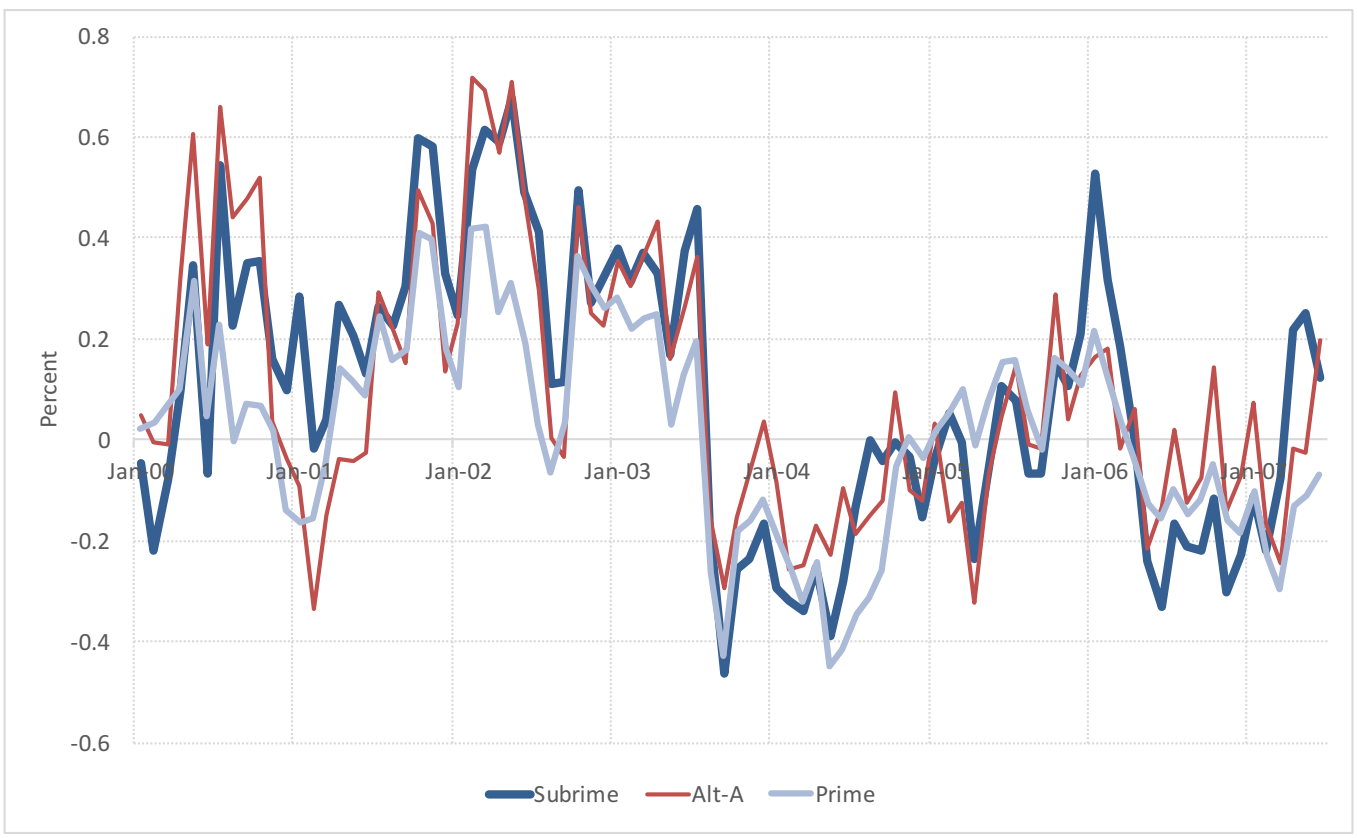

FiguRE 4.5. Average residuals by collateral type.

individual loans, but with somewhat lesser detail on loan and borrower characteristics relative to the PLSD. This information is collected by Black Knight Financial Services (formerly known as Lender Processing Services Inc. (LPS) Applied Analytics; McDash Analytics) and it reaches back to 1992, although we focus again on the period between 2000 and 2007.

As in Antinolfi et al. (2016), we use the RMSD to obtain information about mortgages held in banks' portfolios, or sold to the GSEs to become part of agency MBS. For this classification we define the loans as "agency" or "portfolio" mortgages based on who owns them six months after origination, as in Amromin and Kearns (2014).

Using these data, we re-estimate equation (3.1) separately for agency and portfolio loans. The average residuals from this regression are plotted in figure 4.6, together with the average residuals from the baseline specification estimated using private-label loans. The spread on agency and portfolio loans also declines in 2003, but by a smaller amount and less abruptly than for private-label products, suggesting that the conundrum was primarily a phenomenon affecting mortgages in private-label securitizations. This fact is important, because private-label securitization took off exactly between 2003 and 2004, and quickly 


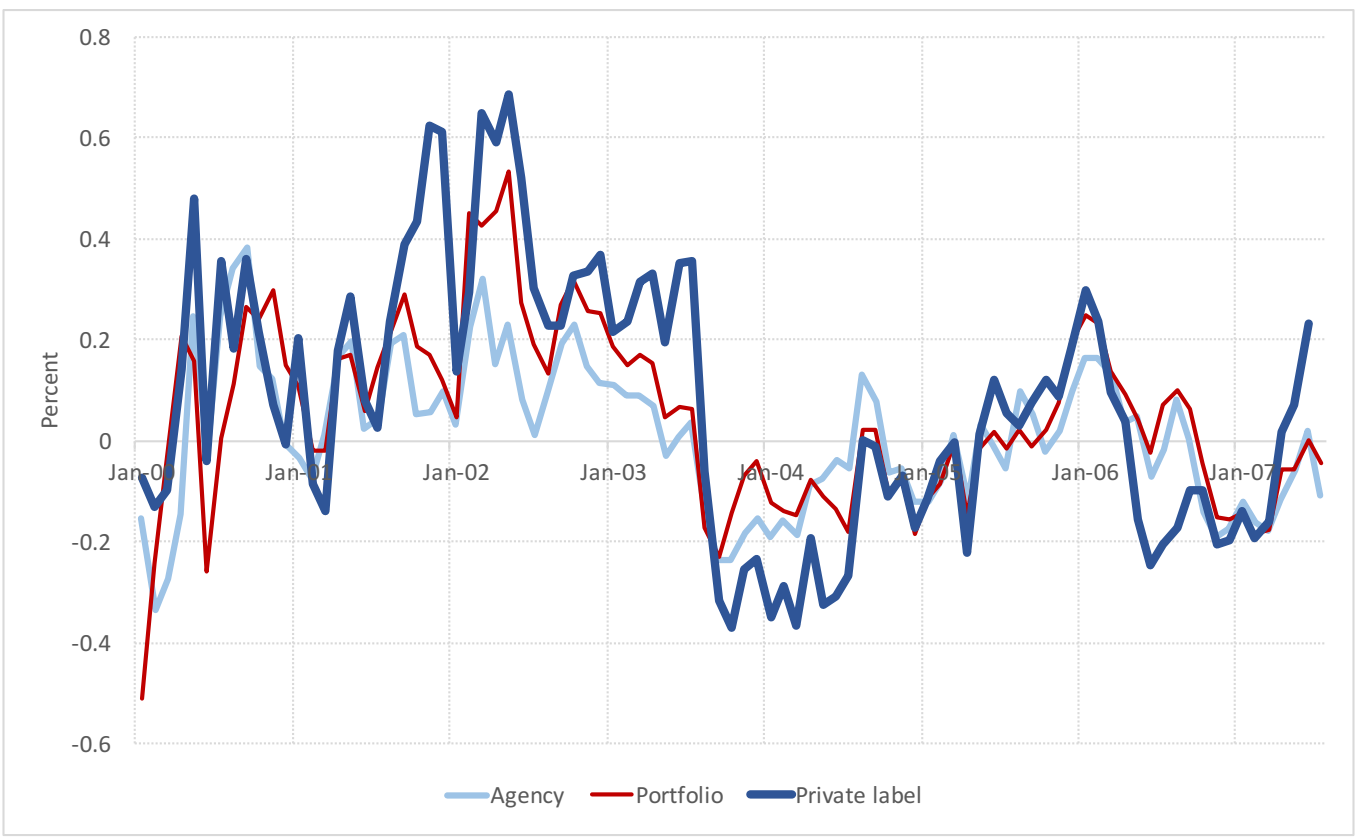

FIGURE 4.6. Average residuals for agency, private-label and portfolio mortgages.

climbed to represent more than 50 percent of the securitization market, before collapsing in 2007 with the financial crisis (figure 1.2).

\section{The Summer of 2003: A Turning Point of the Credit Boom}

The empirical results presented in the previous sections suggest that mortgage rates disconnected from Treasuries in mid 2003, and that this gap closed only around 2006. In this section, we discuss in more detail the timing of this disconnect and its relationship with other important developments in mortgage markets around the same time. We conclude from this investigation that the summer of 2003 was a crucial turning point in the development of the credit boom, as systematically confirmed by industry contacts that we interviewed for this project. This was mainly due to a shift in the behavior of mortgage lenders, which is most evident in the loan-level interest rate data that are the focus of this paper.

We begin by discussing the exact timing of the sharp fall in the conditional mortgage rate spread, which we estimated as taking place in August 2003. Recall that we model mortgage rates observed in the month of the deal closing as a function of lagged Treasury factors. This lag accounts for the fact that the mortgage terms are typically "locked in" a few weeks before the actual closing, and thus they are influenced by conditions at that 


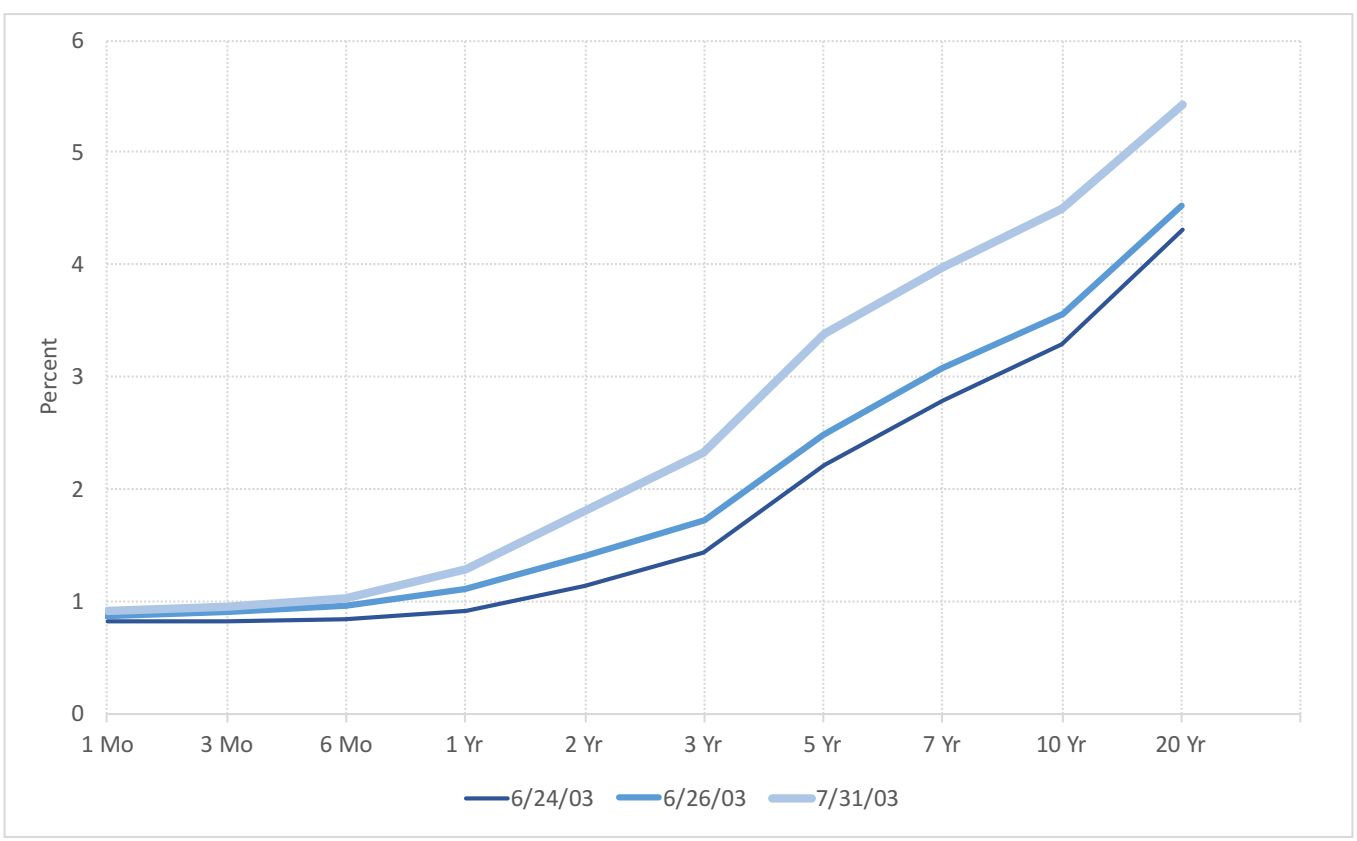

FiguRE 5.1. Treasury yield curve in June and July 2003.

time. Therefore, the initial decoupling between mortgage and Treasury rates must have occurred in July 2003.

This dating of the emergence of the mortgage conundrum is especially notable because it immediately follows the FOMC meeting of June 24-25, 2003. At that meeting, the Committee decided to cut the federal funds rate by 25 basis point, from 1.25 to 1 percent. This was going to be the lowest level reached by the policy rate over the course of that cycle, a fact that became progressively clearer to market participants during the following days and weeks. As a result, the Treasury yield curve steepened significantly over the course of the following month, as shown in figure 5.1. Already on the day of the policy decision, the 10-year Treasury yield increased by 15 basis points. This represents a very large surprise to the market, corresponding to more than two standard deviations of the daily change in this yield on FOMC meeting dates between 1994 and 2007. In the following weeks rates continued to rise and, by the end of July, long-term Treasury yields had increased by more than 100 basis points, reflecting an upward revision in the expectations about the future path of the policy rate. As shown in the previous section, though, mortgage rates barely reacted to this significant tightening in credit conditions in the Treasury market, leading to a large drop in their conditional spread over the Treasury factors. 


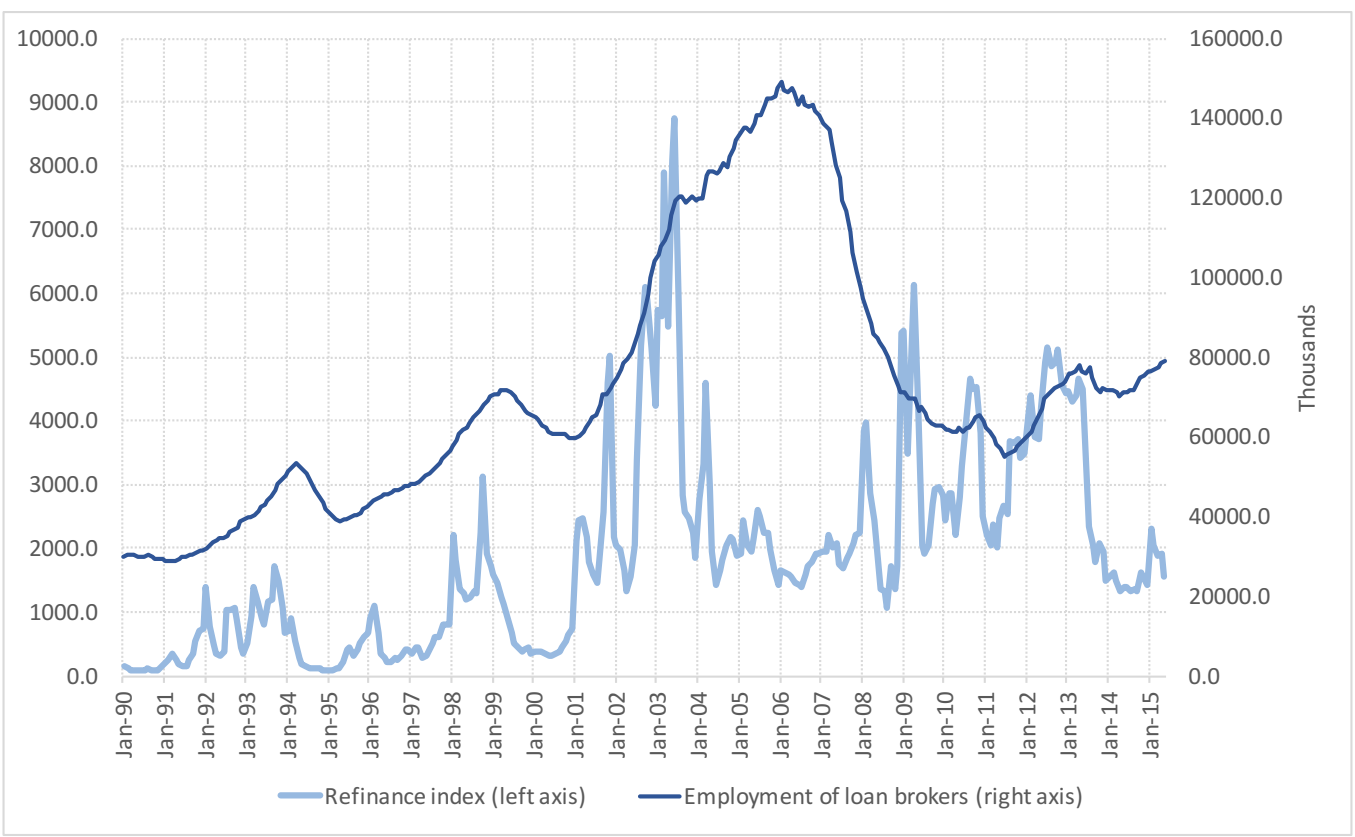

FiguRE 5.2. Mortgage Bankers Association refinance index: Volume of mortgage loan applications for refinancing (seasonally adjusted, Mar-16-1990=100); and employment of mortgage and nonmortgage loan brokers (thousands, seasonally adjusted).

Another consequence of the realization after the June FOMC meeting that policy rates were unlikely to fall any further was the end of the refinancing wave that had been surging to unprecedented levels since 2002. Figure 5.2 shows that the Mortgage Bankers Association refinance index reached an all-time high in June 2003, from which it dropped precipitously immediately following the FOMC meeting.

However, employment among loan brokers did not fall after the refinancing boom came to an end, as also illustrated in figure 5.2. This stability is in contrast with the pattern observed at the end of the previous two refinancing waves in 1994 and 1999, when employment in the sector fell significantly in response to a sharp reduction in the level of refinancing activity. In fact, the number of loan brokers was roughly stable in the second half of 2003 and then rose again until early 2006. This discontinuity in the correlation between sectoral employment and the level of refinancing activity in the summer of 2003 is all the more notable given the extremely large and sudden drop in the latter, which dwarfs the magnitude of the two previous episodes.

Instead of reducing employment and overall activity in response to the disappearance of refinancing opportunities, as they had done in previous similar episodes, mortgage lenders 
appear to have redirected some of their resources towards the origination of new mortgages. The issuance of agency MBS fell very significantly after the end of the refinancing wave, in response to a dearth of conforming raw material to securitize (figure 1.2). In contrast, nonagency securitizations grew rapidly in 2003 and 2004, gaining a sizable market share (figure 1.2). It follows that the majority of the newly originated loans after the summer of 2003 were the non-conforming products that fed private-label MBS. This shift in the absolute and relative supply of non-conforming loans is also reflected in the behavior of the conditional mortgage spreads that we computed in section 4. In fact, a mortgage conundrum appears at the same time both among the conforming loans in the RMSD and among the privately securitized ones in the PLSD, but it is more pronounced among the latter, especially those designated as subprime (figures 4.5 and 4.6). This push by mortgage lenders into new markets is also confirmed by the findings of Scharfstein and Sunderam (2015), who observe a sharp increase in competitive pressures in local mortgage markets between 2003 and 2004 (figure 1 in their paper). ${ }^{10}$

In summary, the sequence of events that we have just reviewed suggests that the mortgage industry underwent a significant change in focus in the summer of 2003, when the end of the monetary policy easing cycle brought the ongoing massive refinancing wave to its abrupt conclusion. Following this drop in the refinancing business, lenders shifted their attention towards subprime borrowers and other previously underserved segments of the mortgage market by keeping mortgage rates low especially for those borrowers, in the face of an increase in Treasury rates.

\section{Consequences for Loan Quality}

What were the consequences of this shift in the supply of credit towards marginal borrowers? Demyanyk and Van Hemert (2011), Foote et al. (2012), Santos (2015) and Palmer (2015), among others, have documented the steady deterioration in the performance of

\footnotetext{
${ }_{10} \mathrm{An}$ important open question is why mortgage lenders shifted into non-conforming loans precisely at this time. One obvious consideration is that the volume of business generated by refinancing activity over the previous two years was probably more than they could handle. As the refinancing wave surged, however, issuing non-conforming loans had probably become a gradually more attractive and accessible business, for reasons that have already been explored in the literature (e.g. Shin, 2012, Bernanke et al., 2011, Foote et al., 2012). Therefore, this push into more marginal borrowers probably appeared like a more viable substitute for the lost refinancing business in the summer of 2003 than it might have been before.
} 


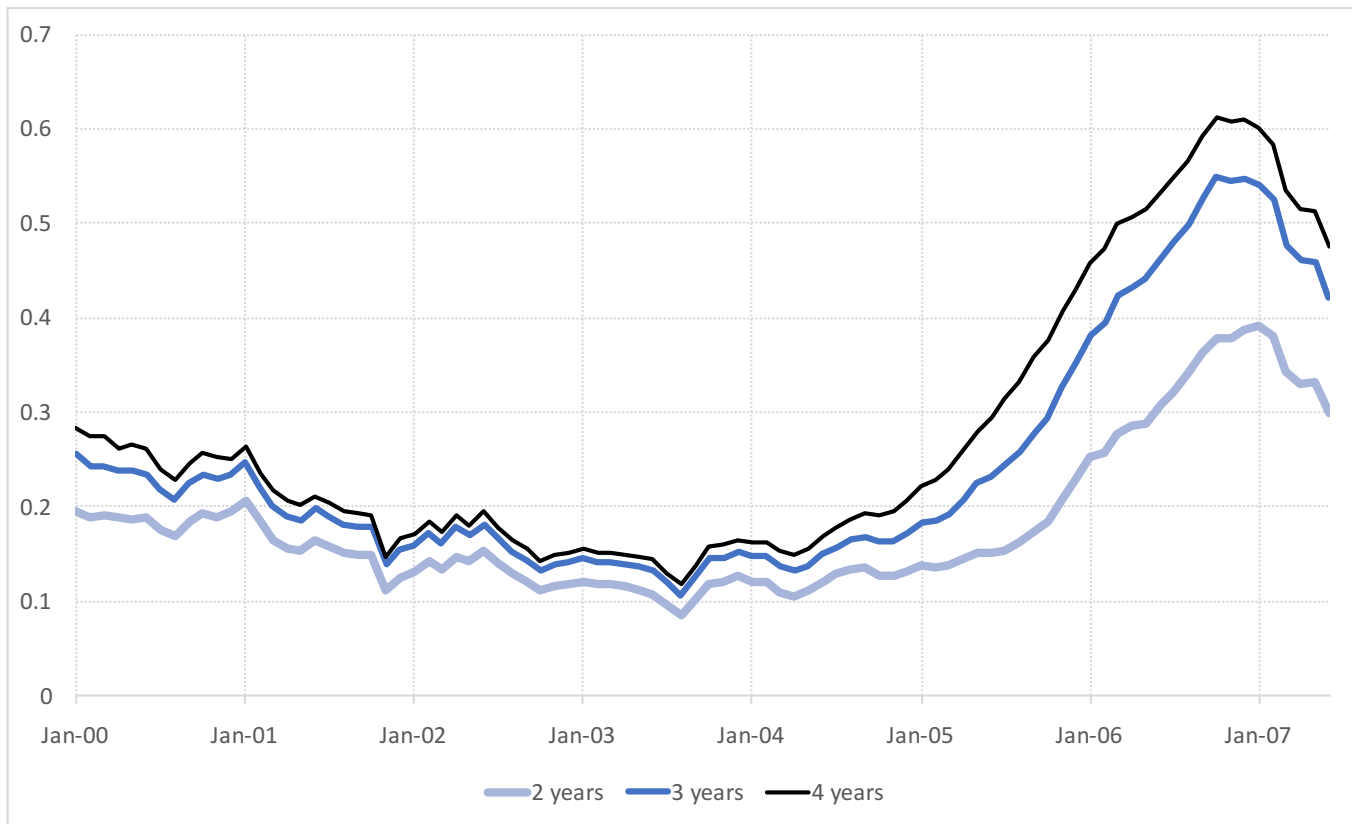

Figure 6.1. Delinquency rates within 2, 3 and 4 years of origination, as a function of the origination date.

mortgages originated over the course of the boom, in terms of delinquencies and foreclosures. ${ }^{11}$ This section complements this literature by demonstrating that this process of progressive deterioration started exactly in the middle of 2003, right after the emergence of the mortgage rate conundrum.

Figure 6.1 offers a preliminary look at the raw data by plotting the fraction of mortgages in our PLSD dataset becoming delinquent within 2, 3 and 4 years of origination, as a function of their date of issuance. In this analysis, a mortgage is defined delinquent if its payments are sixty or more days late, or if it is reported as being in foreclosure, real-estateowned, or in default. The figure shows that delinquency rates declined slowly in the first part of the 2000s, but started to rise for loans originated immediately after the summer of 2003. Mortgages issued around 2006 performed particularly poorly, as it is well-known, also due to the subsequent plunge in property values and deep recession.

To control for the impact of these time-varying economic conditions, we follow Demyanyk and Van Hemert (2011) and study the frequency of mortgage delinquencies by estimating

\footnotetext{
${ }^{11}$ More recently, Ospina and Uhlig (2017) have studied the implications of this deterioration in mortgage performance on the losses sustained by private label RMBS, based on a carefully constructed dataset that includes the near universe of non agency securitizations up to 2013. They find that RMBS losses were roughly stable up to 2003 and started increasing for securities issued from 2004/5 onwards, especially for the lower rated tranches (see their Figure 6).
} 
a proportional odds model of the form

$$
p_{i, t, a}=\Lambda\left(d_{a}+d_{t}+z_{i, t}^{\prime} \theta+w_{i, t, a}^{\prime} \xi\right)
$$

where $\Lambda$ is the cdf of the standard logistic distribution. In this equation, $p_{i, t, a}$ denotes the probability that loan $i$, originated in quarter $t$, becomes delinquent for the first time at age $a ; z_{i, t}$ and $w_{i, t, a}$ are two sets of controls that include all the loan and borrower characteristics listed in table 1, as well as the percent changes in income and house prices between $t$ and $t+a$ in the county where the mortgage was issued; $d_{a}$ and $d_{t}$ are the coefficients of an age and an origination dummy. Differently from Demyanyk and Van Hemert (2011), our baseline estimation of model (6.1) uses a 40 percent random sample of all mortgages in the PLSD database, rather than focusing only on one million subprime loans. In addition, we track mortgage performance for up to four years after origination, since we have now been able to observe the loans for longer, yielding a sample of 95 million quarterly performance records. Finally, we estimate the effect of quarterly, rather than annual, origination dummies, to gain some insights into what happened within 2003.

The first panel of figure 6.2 visualizes the estimated impact of loan and borrower characteristics $\left(z_{i, t}\right)$ on the probability of delinquency within 2 to 4 years, for mortgages issued since 2000. The evolution of these observable traits drives a decline in delinquency rates up to the middle of 2003, and a slow increase after this date. Towards the end of 2006, observable characteristics again contribute to push delinquency rates down, since the onset of the financial crisis led originators to issue safer loans. The process of progressive deterioration in credit quality starting in the middle of 2003 is even more evident when focusing on the unobservable factors, captured by the origination dummies $\left(d_{t}\right)$. This is illustrated in the second panel of 6.2 , which plots the estimated vintage effect on the cumulative delinquency rates. This effect is constant for the early origination vintages, but it starts increasing steadily right after the summer of $2003 .^{12}$

\footnotetext{
${ }^{12}$ As described in equations (10)-(12) of Demyanyk and Van Hemert (2011), the cumulative probability of delinquency within $A$ quarters of origination is equal to one minus the survival rate, i.e. $P_{t, A}^{j} \equiv 1-\prod_{a=0}^{A}\left(1-\pi_{t, a}^{j}\right)$. To visualize the role of observable characteristics and the vintage effect, figure 6.2 plots $P_{t, A}^{o}$ and $P_{t, A}^{u}$, computed using $\pi_{t, a}^{o}=\Lambda\left(\Lambda^{-1}\left(\bar{\pi}_{a}\right)+\bar{z}_{t}^{\prime} \hat{\theta}-\bar{z}^{\prime} \hat{\theta}\right)$ and $\pi_{t, a}^{u}=\Lambda\left(\Lambda^{-1}\left(\bar{\pi}_{a}\right)+\hat{d}_{t}-\bar{d}\right)$ respectively. In these expressions, $\bar{\pi}_{a}$ is the unconditional frequency of experiencing a first-time delinquency at age $a, \hat{\theta}$ is the estimate of $\theta, \bar{z}_{t}$ is the time- $t$ average of the observable loan and borrower characteristics, $\bar{z}$ is the mean of $\bar{z}_{t}$ over time, $\hat{d}_{t}$ are the estimated coefficients on the origination dummies, and $\bar{d}$ is their mean over time.
} 

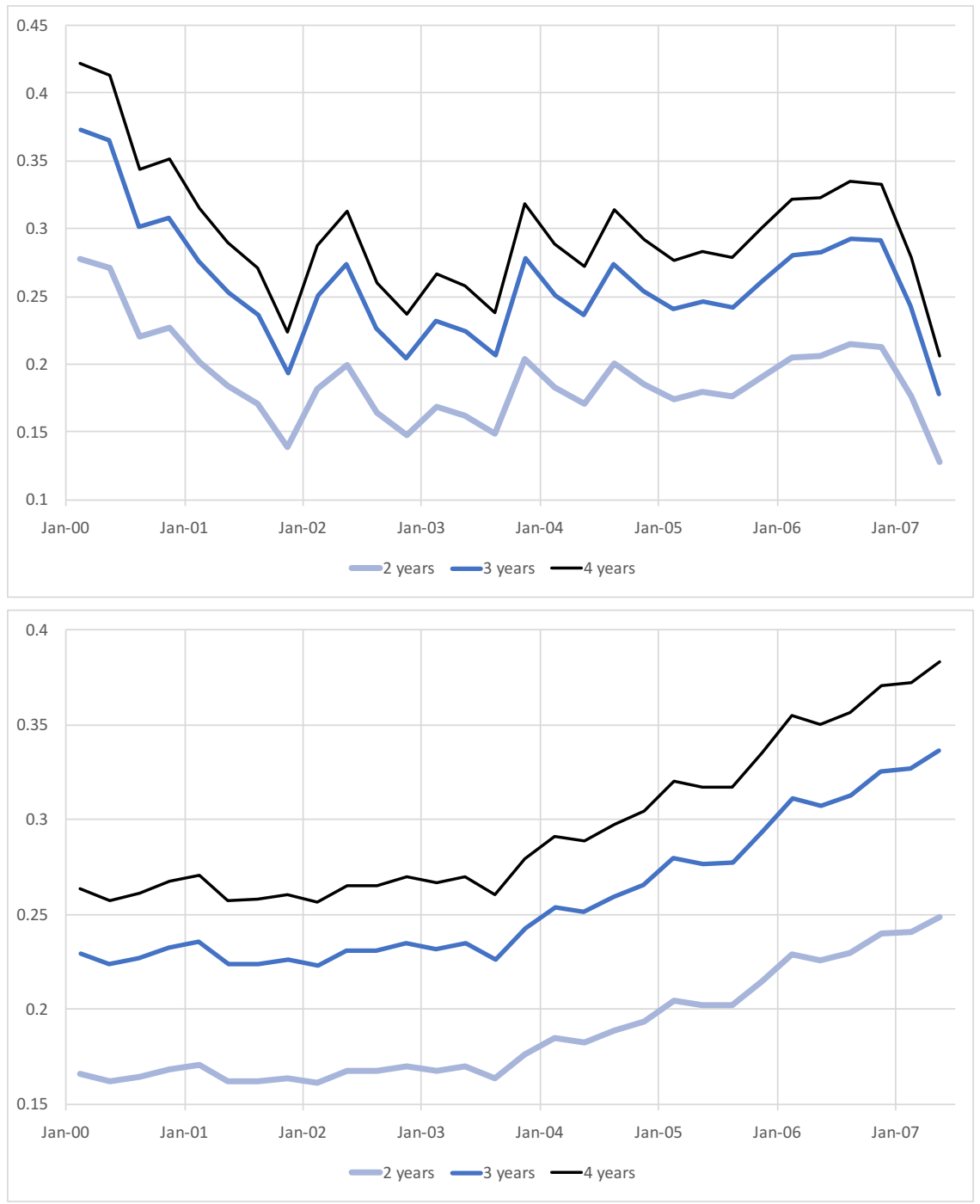

FIgURE 6.2. Estimated effect of observable loan/borrower characteristics (upper panel) and vintage dummies (lower panel) on 2, 3 and 4-year cumulative delinquency rates.

These findings suggests that the (conditionally) cheaper mortgages that started being offered in the summer of 2003, turned out to be of progressively lower average quality, as measured by their ex-post performance. This lower quality was partly reflected in some of the observable characteristics included in equation (6.1). For instance, there was an increase in the incidence of mortgages with no documentation and with non-traditional features such as low amortization. In addition, figure 6.2 indicates that a notable deterioration in credit quality also happened along dimensions that are not spanned by the controls, and that are 
captured instead by the origination dummy. Finally, a closer inspection of these patterns reveals that this phenomenon was especially pronounced for subprime mortgages.

In summary, the sharp and persistent decline in conditional mortgage rates documented above was accompanied by a worsening of the observable and unobservable quality of the credit being extended. A natural interpretation of these facts is that the summer of 2003 witnessed a shift in the supply of credit that ultimately resulted in the origination of mortgages with lower interest rates and of worse overall quality. As shown in section 5, a majority of these mortgages were non-conforming and were thus absorbed by private-label securitization pools. The fact that an important dimension of these loans' lower quality was not publicly observable helps to explain why these MBS performed especially poorly.

\section{LESSONS LEARNED}

This paper contributes to the literature documenting the shift in the supply of credit towards marginal borrowers during the US housing boom. What we add to this literature, through our focus on loan-level interest rates and their conditional spread over Treasuries, is a sharper identification of the timing of this discontinuity, and of some of the factors behind it. In terms of timing, we pin-point the emergence of the conundrum to July 2003, and highlight that a process of progressive credit quality deterioration started immediately after this date. In terms of factors, we relate the conundrum to the attempt of originators to sustain their level of activity by entering new markets, following the collapse of the refinancing business.

A further contribution of this analysis is to refine our understanding of the role of monetary policy during the credit boom. According to a popular narrative, the Federal Reserve was instrumental to the boom since it kept the policy rate "too low for too long" over that period (e.g. Taylor, 2007), especially when the federal funds rate marched gradually upwards starting in 2004, at a pace that the FOMC described as "likely to be measured" (see FOMC statement of June 30, 2004). According to our results, this narrative misses a crucial element: after the summer of 2003, mortgage rates were low by up to 100 basis points even compared to the behavior of Treasury factors. This fact, in turn, suggests that some emphasis in our attempts to reconstruct the chain of events that led to the credit boom should be shifted towards the behavior of mortgage lenders in the summer of 2003, and their response to the end of the easing cycle. 
REFERENCES

Amromin, E. And C. Kearns (2014): "Access to Refinancing and Mortgage Interest Rates: HARPing on the Importance of Competition," Working Paper Series WP-201425, Federal Reserve Bank of Chicago.

Antinolfi, G., C. Brunetti, And J. Im (2016): "Mortgage Rates and Credit Risk: Evidence from Mortgage Pools," Mimeo, Washington University in St. Louis.

Bernanke, B. S., C. Bertaut, L. P. Demarco, and S. Kamin (2011): "International capital flows and the returns to safe assets in the United States, 2003-2007," International Finance Discussion Papers 1014, Board of Governors of the Federal Reserve System (U.S.).

Demyanyk, Y. And O. Van Hemert (2011): "Understanding the Subprime Mortgage Crisis," Review of Financial Studies, 24, 1848-1880.

Foote, C. L., K. S. Gerardi, And P. S. Willen (2012): "Why did so many people make so many ex post bad decisions?: the causes of the foreclosure crisis," Public Policy Discussion Paper 12-2, Federal Reserve Bank of Boston.

Gilchrist, S. And E. Zakrajsek (2012): "Credit Spreads and Business Cycle Fluctuations," American Economic Review, 102, 1692-1720.

Greenspan, A. (2005): "Federal Reserve Board's semiannual monetary policy report to the Congress: testimony before the Committee on Banking, Housing, and Urban Affairs, U.S. Senate, February 16, 2005," Speech 59, Board of Governors of the Federal Reserve System (U.S.).

Keys, B. J., T. Piskorski, A. Seru, And V. Vig (2012): "Mortgage Financing in the Housing Boom and Bust," in Housing and the Financial Crisis, National Bureau of Economic Research, Inc, NBER Chapters, 143-204.

Landvoigt, T., M. Piazzesi, And M. Schneider (2015): "The Housing Market(s) of San Diego," American Economic Review, 105, 1371-1407.

Mian, A. And A. Sufi (2009): "The Consequences of Mortgage Credit Expansion: Evidence from the U.S. Mortgage Default Crisis," The Quarterly Journal of Economics, 124, 1449-1496.

Mian, A. R. And A. Sufi (2015): "Fraudulent Income Overstatement on Mortgage Applications during the Credit Expansion of 2002 to 2005," NBER Working Papers 20947, National Bureau of Economic Research, Inc. 
Ospina, J. And H. Uhlig (2017): "Mortgage-Backed Securities and the Financial Crisis of 2008: a Post Mortem," Mimeo, University of Chicago.

Palmer, C. (2015): "Why Did So Many Subprime Borrowers Default During the Crisis: Loose Credit or Plummeting Prices?" Mimeo, University of California at Berkeley.

SAntos, T. (2015): "Credit booms: implications for the public and the private sector," BIS Working Papers 481, Bank for International Settlements.

Scharfstein, D. And A. Sunderam (2015): "Market Power in Mortgage Lending and the Transmission of Monetary Policy," Mimeo, Harvard Business School.

Shin, H. S. (2012): "Global Banking Glut and Loan Risk Premium," IMF Economic Review, 60, 155-192.

TAYlor, J. B. (2007): "Housing and monetary policy," Proceedings - Economic Policy Symposium - Jackson Hole, 463-476.

Federal Reserve Bank of Chicago

E-mail address: ajustiniano@frbchi.org

Northwestern University, CEPR, And NBER

E-mail address: g-primiceri@northwestern.edu

Federal Reserve Bank of New York

E-mail address: a.tambalotti@gmail.com 